\title{
C4B null alleles are not associated with genetic polymorphisms in the adjacent gene CYP2 IA2 in autism
}

\author{
Thayne L Sweeten ${ }^{1}$, Daniel W Odell ${ }^{1,2}$, J Dennis Odell ${ }^{1}$ and \\ Anthony R Torres*1
}

\begin{abstract}
Address: ${ }^{1}$ Center for Persons with Disabilities, Utah State University, 6895 Old Main Hill, Logan, UT 84322-6895, USA and ${ }^{2}$ Department of Biological Engineering, Utah State University, 4105 Old Main Hill, Logan, UT 84322-4105, USA

Email: Thayne L Sweeten - thayne@cpd2.usu.edu; Daniel W Odell - dan@cpd2.usu.edu; J Dennis Odell - dennis@cpd2.usu.edu; Anthony R Torres* - rtorres@cpd2.usu.edu

* Corresponding author
\end{abstract}

Published: 7 January 2008

BMC Medical Genetics 2008, 9:1 doi:10.1 I86/147|-2350-9-1
Received: I August 2007

Accepted: 7 January 2008

This article is available from: http://www.biomedcentral.com/I47/-2350/9/I

(c) 2008 Sweeten et al; licensee BioMed Central Ltd.

This is an Open Access article distributed under the terms of the Creative Commons Attribution License (http://creativecommons.org/licenses/by/2.0), which permits unrestricted use, distribution, and reproduction in any medium, provided the original work is properly cited.

\begin{abstract}
Background: Research indicates that the etiology of autism has a strong genetic component, yet so far the search for genes that contribute to the disorder, including several whole genome scans, has led to few consistent findings. However, three studies indicate that the complement C4B gene null allele (i.e. the missing or nonfunctional $C 4 B$ gene) is significantly more frequent in individuals with autism. Due to the close proximity of the CYP2 IA2 gene to the C4B locus $(3 \mathrm{~kb})$ it was decided to examine samples from autistic subjects, including many with known C4B null alleles for common CYP2 IA2 mutations.
\end{abstract}

Methods: Samples from subjects diagnosed with autism and non-autistic controls (controls) previously typed for C4B null alleles were studied. Allele specific polymerase chain reaction (PCR) methods were used to determine 8 of the most common CYP2 IA2 genetic mutations, known to completely or partially inhibit 2 I-hydroxylase, the enzyme encoded by the CYP2 IA2 gene.

Results: Although the combined autism and control study subjects had 50 C4B null alleles only 15 CYP2 IA2 mutations were detected in over 2250 genotypes. Eight mutations were detected in the autistic samples and 7 in the controls. The frequency of CYP2 IA2 mutations was similar between the autism and control samples. Only one individual (autistic) carried a chromosome containing both C4B null allele and CYP2 IA2 mutations.

\section{Background}

Autism is a severe neurodevelopmental disorder that is approximately four times more common in males than females. The current prevalence for the disorder is approximately 1 in 152 children [1]. Although there are various mechanisms that can lead to this behaviorally defined condition, in most cases the etiology remains unknown. A strong genetic component clearly exists [2]; however, con- sistent detection of disease associated genetic variants has rarely been reported. Whole genome scans using microarray technology may better detect the genetic contributions to autism susceptibility [3].

Genes located in the RCCX module found on chromosome 6 in the human leukocyte antigen (HLA) locus are associated with various disease states $[4,5]$. This module 
contains the genes RP, C4, CYP21, and TNX (abbreviated RCCX) in a contiguous sequence. Different variants of these four genes can exist in the RCCX module including $R P 1$ or RP2, C4A or C4B (long or short), CYP21A2 or CYP21A1P, and TNXA or TNXB. RP2 and TNXA are gene fragments while CYP21A1P is a pseudogene. A single chromosome usually contains one, two, three RCCX modules in tandem, but rare cases can have four modules.

Because of the diversity in the number and size of the RCCX modules misalignments and unequal crossovers occur during meiosis resulting frequently in deletions, conversions, duplications along with the acquisition of mutations from nearby pseudogenes or gene segments [6]. One such mutation in this module is the missing/ nonfunctional $C 4 A$ or $C 4 B$ gene ( $C 4$ null allele). Therefore, the $C 4$ containing complex is an extraordinarily complex region of the human genome [7] (Figure 1).

The RCCX module may play a significant role in the genetic underpinnings of autism. Several studies have

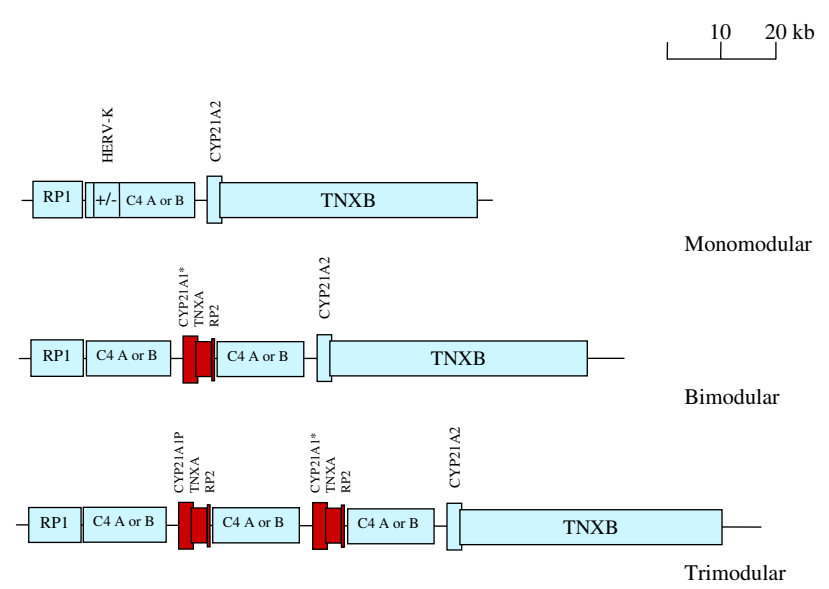

Figure I

Three common arrangements of the RCCX module. Monomodular, bimodular, and trimodular are present in about 17, 69 and 14\% of chromosomes, respectively [7]. The C4 gene which is either C4A or C4B can be either a long or short variant depending upon the presence of a $6.36 \mathrm{~kb}$ endogenous retrovirus, HERV-K(C4). Pseudogenes or gene fragments are red. CYP2 IAI* indicates either a CYP2 IAIP pseudogene or the CYP2 IA2 gene. In the present study 40 chromosomes from autistic individuals had a $C 4 B$ null allele. Of these chromosomes 19 were monomodular and 21 were bimodular. In the control subjects with $C 4 B$ null alleles 10 chromosomes were monomodular and I was bimodular. Bimodular C4B null alleles were significantly more frequent in autistic subjects compared to controls $(P=0.0001)$. No $C 4 B$ null alleles or CYP2 IA2 mutations were detected in the subjects ( 2 autistic, 4 control) with trimodular RCCX modules, determined by protein immunofixation electrophoresis [I0]. shown that the frequency of $C 4 B$ null alleles is increased in individuals with autism [8-10], the most recent of which found that $42.4 \%$ of autistic subjects carry a $C 4 B$ null allele compared to $14.5 \%$ of controls [10]. The CYP21A2 gene is located approximately $3 \mathrm{~kb}$ downstream of $C 4$ and the concurrent deletion of $C 4 B$ with portions of the CYP21A2 has been described $[11,12]$. Therefore, the aim of the present research was to determine if the $C 4 B$ null allele, found frequently in subjects with autism, is associated with CYP21A2 mutations. As well, the overall frequency of CYP21A2 mutations in autistic verses control subjects was determined.

C4 genes encode innate immune $\mathrm{C} 4$ proteins that are important in the complement cascade. CYP21A2 encodes an enzyme, 21-hydroxylase, which is important in the synthesis of cortisol and in maintaining proper androgen levels.

Over 2,250 genetic typings of CYP21A2 mutations were completed in 80 autistic and 60 controls subjects that had previously been typed for $C 4 B$ null alleles [10]. Fifteen total CYP21A2 mutations where detected; however, only one individual (autistic) carried a chromosome containing both a $C 4 B$ null allele and CYP21A2 mutations. Therefore, in these subjects it does not appear that $C 4 B$ null alleles are associated with the CYP21A2 mutations studied.

\section{Methods \\ Subjects}

This study utilized samples previously characterize for $C 4 A$ and $C 4 B$ null alleles in an autism case-control study [10]. Autistic subjects and controls were Caucasian of Northern European descent and IRB (Utah State University) approval was obtained for this study. As reported, the subjects were diagnosed with autism using DSM-IV criteria by pediatric psychiatrists and psychologists expert in the evaluation of autism. The Autism Diagnostic Observation Schedule (ADOS) [13] and the Autism Diagnostic Inventory (ADI) [14] confirmed the Diagnosis. Various CYP21A2 genetic determinations were completed in 80 individuals with autism ( 8 female, 72 male) and 60 control subjects ( 15 female, 45 male). Parents of the particular subjects were typed if their child was positive for a mutation.

\section{DNA preparation}

DNA samples were extracted from peripheral blood mononuclear cells as previously described [15]. To genotype samples with limited amounts of DNA, whole genome amplification was performed using multiple displacement amplification (MDA) based on the method of Dean et al.[16]. MDA was performed using RepliPHI ${ }^{\mathrm{TM}} \mathrm{Phi}$ 
29 Reagent Sets (Epicentre ${ }^{\circledR}$ Technologies, Madison, Wisconsin).

PicoGreen ${ }^{\circledast}$ quantitation of amplified DNA was performed using a Quant-iT ${ }^{\mathrm{TM}}$ DNA Assay Kit from Molecular Probes $^{\mathrm{TM}}$ (Eugene, Oregon) according to kit protocol. Fluorescence was measured with a Synergy HT microplate reader (BIO-TEK ${ }^{\circledast}$, Winooski, Vermont).

\section{Polymerase chain reaction}

Seven mutations were determined by allele-specific polymerase chain reaction (PCR) based on the method of Wilson et al.[17]. This method is as accurate as the dot blot procedure [17]; therefore, it is sensitive enough to detect a mutation in only one CYP21A2 gene if more than two copies of the gene are present. The mutations analyzed included amino acid substitutions (P30L, I172N, V281L, R356W, exon 6 cluster mutation (L236N, V237Q, M239K)), a splicing mutation (intron 2 (656) A/C to G), and a deletion (exon 3, 8 base pair deletion). Each reaction contained a primer specific for either the common or rare genetic variant in conjunction with a primer that amplified only the CYP21A2 gene and not the pseudogene (Table 1). A PCR based assay for detection of a $30 \mathrm{~kb}$ deletion/conversion affecting both C4B and CYP21A2 was performed based upon the method described in KeenKim et al.[18].

\section{Statistics}

Chi-square analysis along with the Fisher's Exact Test where performed using SPSS 14 (SPSS Inc., Chicago, Illinois). A two-tailed test with a P-value of $<0.05$ was considered significant after Bonferoni corrections for multiple comparisons.

\section{Results and discussion}

Although the 80 autistic individuals studied had $40 \mathrm{C} 4 \mathrm{~B}$ null alleles and the 60 control individuals had $10 C 4 B$ null alleles only 15 total CYP21A2 mutations were detected in over 2250 genotypes. Eight CYP21A2 mutations were detected in the autistic subjects and 7 in the controls (Table 2). Only one individual (autistic) had a chromosome carrying both a $C 4 B$ null allele and a CYP21A2 mutation. Therefore, no association was determined between C4B null alleles and CYP21A2 mutations in the study subjects.

Overall, the number of CYP21A2 mutations did not differ between the autism and control groups and no group differences were found in frequencies of individual CYP21A2 mutations. The frequency of CYP21A2 mutations seen in this research is similar to general population frequencies reported by others [19]. Five individuals with autism $(6.25 \%)$ and five controls $(8.33 \%)$ carried a CYP21A2 mutation. Two individuals with autism and one control

Table I: Sequences of oligonucleotide primers for allele-specific PCR

\begin{tabular}{|c|c|c|c|}
\hline CYP2IA2 Mutations [ref] & rs \# & Primer & 5'-Sequence-3' \\
\hline \multirow[t]{3}{*}{$30 \mathrm{~kb}$ deletion [ 18$]$} & & common forward & gcttcttgatgggtgatcaat \\
\hline & & rare forward & tccccaatccttactttttgtc \\
\hline & & reverse & cctcaatcctctgcagcg \\
\hline \multirow[t]{3}{*}{ V28IL [I7] } & rs647I & common reverse & tccactgcagccatgtgcac \\
\hline & & rare reverse & tccactgcagccatgtgcaa \\
\hline & & forward & gagggatcacatcgtcgtggagatg \\
\hline \multirow[t]{3}{*}{ II72N [17] } & rs34607927 & common forward & tcctcacctgcagcatcat \\
\hline & & rare forward & ctctcctcacctgcagcatcaa \\
\hline & & reverse & agctgcatctccacgatgtga \\
\hline \multirow[t]{3}{*}{ R356W [17] } & & common reverse & ctaagggcacaacgggccg \\
\hline & & rare reverse & ctaagggcacaacggggcca \\
\hline & & forward & gagggatcacatcgtcgtggagatg \\
\hline \multirow[t]{3}{*}{ P30L [17] } & & common forward & tccggagcctccacctccc \\
\hline & & rare forward & tccggagcctccacctcct \\
\hline & & reverse & agctgcatctccacgatgtga \\
\hline \multirow[t]{4}{*}{ IN2 (656) A/C to G [17] } & & common forward $(A)$ & ttcccaccctccagcccccaa \\
\hline & & common forward (C) & ttcccaccctccagcccccac \\
\hline & & rare forward & ttcccaccctccagcccccag \\
\hline & & reverse & agctgcatctccacgatgtga \\
\hline \multirow[t]{3}{*}{ Ex 3 (8 bp deletion) [17] } & & common forward & cggacctgtccttgggagactac \\
\hline & & rare forward & actacccggacctgtccttggtc \\
\hline & & reverse & agctgcatctccacgatgtga \\
\hline Ex 6 cluster & & (see reference 17 for & \\
\hline L236N & & common reverse & agctgcatctccacgatgtga \\
\hline V237Q & rs 12530380 & rare reverse & tcagctgcttctcctcgttgtgg \\
\hline $\mathrm{M} 239 \mathrm{~K}$ & rs6476 & forward & cggacctgtccttgggagactac \\
\hline
\end{tabular}


Table 2: Frequencies of the C4B null allele and CYP2 IA2 mutations

\begin{tabular}{|c|c|c|c|}
\hline & Autism & Control & P-value \\
\hline C4B null allele & $40 / 160$ & $10 / 120$ & $P=0.0003$ \\
\hline $30 \mathrm{~kb}$ deletion/conversion & $1 / 160$ & $2 / 120$ & Not significant (NS) \\
\hline \multicolumn{4}{|l|}{ CYP2 IA2 mutations } \\
\hline V28IL & $3 / 160$ & $1 / 120$ & NS \\
\hline $1172 \mathrm{~N}$ & $1 / 160$ & $2 / 120$ & NS \\
\hline R356W & $1 / 160$ & $0 / 120$ & NS \\
\hline P30L & $2 / 160$ & $1 / 120$ & NS \\
\hline IN2 & $0 / 160$ & $0 / 120$ & NS \\
\hline Ex 3 Del & $0 / 160$ & $\mathrm{I} / \mathrm{I} 20$ & NS \\
\hline Ex 6 cluster & $0 / 160$ & $0 / 120$ & NS \\
\hline
\end{tabular}

subject carried two or three mutations. In these cases the mutations all typed to individual parents. Thus, the multiple mutations were found on single chromosomes. When a mutation was found in the child's DNA it was also present in DNA from one of the parents, thus confirming both accurate typing and absence of de novo mutations in the study children.

HLA extended haplotyes known to contain C4B null alleles are increased in frequency in autistic individuals (i.e. HLA extended haplotypes $35.2(\mathrm{n}=4), 35.3(\mathrm{n}=2), 44.1$ $(\mathrm{n}=8)$, and $58.1(\mathrm{n}=1))$. Extended haplotypes 35.3 and 58.1 have monomodular RCCX structures (C4A: C4B null allele) and extended haplotypes 35.2 and 44.1 are bimodular (C4A, C4A:C4B null allele). No CYP21A2 mutations were observed in these haplotypes.

The HLA 8.1 is present in $10 \%$ of the Caucasian population and represents the most common extended haplotype. It has a monomodular RCCX structure with a C4A null allele and a normal $C 4 B$ gene (C4A null allele: $C 4 B)$. This extended haplotype, referred to as COX in the MHC Haplotype Project [20], has been completely sequenced [21]. Of the eighteen subjects with an 8.1 extended haplotype one had the rare SNP creating the TTG codon that encodes for leucine at position 281 while 17 subjects had the common codon GTG that encodes for valine at position 281. This observation is in agreement with DNA sequencing data that shows low level SNP diversity in 8.1 extended haplotypes from different individuals [22].

The specific CYP21A2 mutations were chosen because they are the most common mutations that result in significant decreases in 21-hydroxylase activity. One of the mutations investigated was a $30 \mathrm{~kb}$ deletion/conversion that deletes $C 4 B$ and converts CYP21A2 into a nonfunctional CYP21A1P/CYP21A2 hybrid with its pseudogene (Figure 2). This mutation was of particular interest because it provides a direct link between a $C 4 B$ null allele

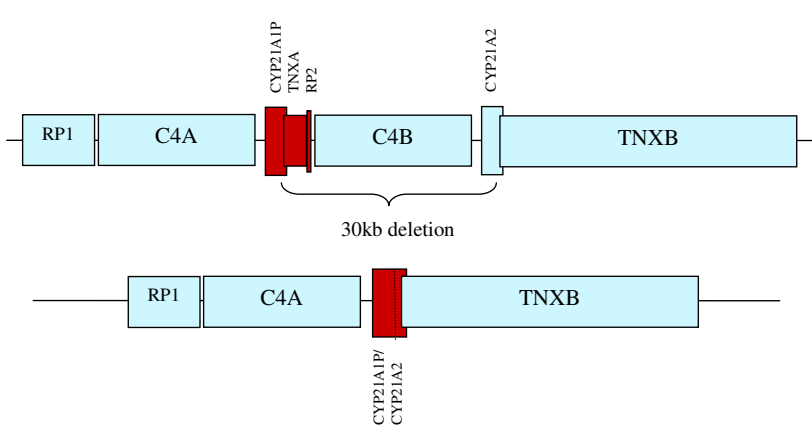

Figure 2

The $30 \mathrm{~kb}$ deletion/conversion of C4B and CYP2 I A2. This diagram depicts the most common arrangement of the RP, C4, CYP2I, and TNX (RCCX) gene module. Pseudogenes or gene fragments are red. The $30 \mathrm{~kb}$ deletion removes part of CYP2 IAIP, TNXA, RP2, C4B and part of CYP2 IA2 leaving a non-protein encoding CYP2 IAIPICYP2 IA2 region.

and a CYP21A2 mutation. One autistic subject and two controls carried this mutation. Again, these three polymorphisms were inherited and did not involve de novo mutations.

It has been reported that two of the mutations, P30L and V281L, partially inhibit 21-hydroxylase activity (30-60\% of normal), whereas the other mutations analyzed cause either complete or nearly complete enzyme inhibition [23]. Four subjects with autism (5\%) carried a partially inhibiting mutation (P30L or V281L) compared to two control subjects $(3.33 \%)$. This difference is not statistically significant.

21-hydroxylase deficiency is the most common cause of congenital adrenal hyperplasia. Some evidence supports the idea of 21-hydroxylase being involved in autism [24], which could result in the excessive androgen production seen in some cases [25] and thereby contribute to disease etiology [26,27]. The present data does not provide genetic support for 21-hydroxylase involvement in autism.

\section{Conclusion}

This study examined both mono and bimodular RCCX genetic modules that contain $C 4 B$ null alleles for mutations in the adjoining CYP21A2 gene. The C4B null alleles seen in autism are not associated with the CYP21A2 genetic mutations examined in this study. The frequency of CYP21A2 mutations was similar between the autism and control groups. Based on family typings no de novo mutations of C4B or CYP21A2 were apparent in study subjects. Therefore, the CYP21A2 mutations studied do not appear to contribute to the etiology of autism. However, a role for CYP21A2 in autism cannot be ruled out as 
other factors affecting CYP21A2 gene expression such as promoter polymorphisms or epigenetic variation were not studied and may be relevant [28]. As well, a weak association may be beyond the statistical power of the present study to detect.

\section{Competing interests}

The author(s) declare that they have no competing interests.

\section{Authors' contributions}

DWO aided in the molecular genetic studies. JDO assigned the C4 typing. ART aided in the study design and assays, coordination the research and helped to draft the manuscript. TLS conceived of the study, carried out the molecular genetic studies, participated in the design, performed the statistical analysis and drafted the manuscript. All authors have read and approved the final manuscript.

\section{Acknowledgements}

This research project was supported with funding from The Jonty Foundation and the Center for Persons with Disabilities (Utah State University). We would like to thank Dr. Dave Ward (Nevada Cancer Institute) and Dr. Jonna Westover (CPD) for their suggestions and aid in preparing the manuscript.

\section{References}

I. Autism and Developmental Disabilities Monitoring Network Surveillance year 2002 Principal Investigators; Centers for Disease Control and Prevention: Prevalence of autism spectrum disordersautism and developmental disabilities monitoring network, 14 sites, United States, 2002. MMWR Surveill Summ 2007, 56:12-28.

2. Folstein S, Rutter M: Infantile autism: a genetic study of $2 I$ twin pairs. J Child Psychol Psychiatry 1977, I 8:297-32I.

3. Jacquemont ML, Sanlaville D, Redon R, Raoul O, Cormier-Daire V, Lyonnet S, Amiel J, Le Merrer M, Heron D, de Blois MC, Prieur M, Vekemans M, Carter NP, Munnich A, Colleaux L, Philippe A: Arraybased comparative genomic hybridisation identifies high frequency of cryptic chromosomal rearrangements in patients with syndromic autism spectrum disorders. J Med Genet 2006, 43:843-849.

4. Yang Y, Chung EK, Zhou B, Lhotta K, Hebert LA, Birmingham DJ, Rovin $\mathrm{BH}, \mathrm{Yu} \mathrm{CY}$ : The intricate role of complement componenet $\mathrm{C} 4$ in human systemic lupus erythematosus. In Complement in Autoimmunity Edited by: Tsokos GC. Basel, Karger; 2004:98-132.

5. White PC, New MI, Dupont B: HLA-linked congenital adrenal hyperplasia results from a defective gene encoding a cytochrome P-450 specific for steroid 2I-hydroxylation. Proc Natl Acad Sci USA 1984, 81:7505-7509.

6. Yang Z, Mendoza AR, Welch TR, Zipf WB, Yu CY: Modular variations of the human major histocompatibility complex class III genes for serine/threonine kinase RP, complement component C4, steroid 2I-hydroxylase CYP2I, and tenascin TNX (the RCCX module). J Biol Chem 1999, 274: I 2 I47- I2I 56.

7. Blanchong CA, Zhou B, Pupert KL, Chung EK, Jones KN, Sotos JF, William BZ, Rennebohm RM, Yu CY: Deficiencies of human complement component C4A and C4B and heterozygosity in length variants of RP-C4-CYP2I-TNX (RCCX) nodules in Caucasians: the load of RCCX genetic diversity on major histocompatibility complex-associated disease. J Exp Med 2000, 191:2183-2196.

8. Warren RP, Singh VK, Cole P, Odell JD, Pingree CB, Warren WL: Increased frequency of the null allele at the complement C4b locus in autism. Clin Exp Immunol 199I, 83:438-440.
9. Warren RP, Singh VK, Averett RE, Odell JD, Maciulis A, Burger RA, Daniels WW, Warren WL: Immunogenetic studies in autism and related disorders. Mol Chem Neuropathol 1996, 28:77-8I.

10. Odell D, Maciulis A, Cutler A, Warren L, McMahon W, Coon H, Stubbs G, Henley K, Torres A: Confirmation of the association of the C4B null allele in autism. Hum Immunol 2005, 66: I 40- I 45.

II. Carroll MC, Palsdottir A, Belt KT, Porter RR: Deletion of complement $\mathrm{C4}$ and steroid 21 -hydroxylase genes in the HLA class III region. EMBO I I 985, 4:2547-2552.

12. Schneider PM, Carroll MC, Alper CA, Rittner C, Whitehead AS, Yunis EJ, Colten HR: Polymorphism of the human complement C4 and steroid 2I-hydroxylase genes: restriction fragment length polymorphisms revealing structural deletions, homoduplications, and size variants. J Clin Invest 1986, 78:650-657.

13. Lord C, Rutter M, Goode S, Heemsbergen J, Jordan H, Mawhood L, Schopler E: The autism diagnostic observation schedule: A standardized observation of communicative and social behavior. J Autism Dev Disord 1989, 19:185-212.

14. LeCouteur A, Rutter M, Lord C, Rios P, Robertson S, Holdgrafer M, McLennan JD: Autism Diagnostic Interview: A semistructured interview for parents and caregivers of autistic persons. J Autism Dev Disord 1989, 19:363-387.

15. Torres AR, Maciulis A, Stubbs EG, Cutler A, Odell D: The transmission disequilibrium test suggests that HLA-DR4 and DRI3 are linked to autism spectrum disorder. Hum Immunol 2002, 63:311-316.

16. Dean FB, Hosono S, Fang L, Wu X, Faruqi AF, Bray-Ward P, Sun Z, Zong Q, Du Y, Du J, Driscoll M, Song W, Kingsmore SF, Egholm M, Lasken RS: Comprehensive human genome amplification using multiple displacement amplification. Proc Natl Acad Sci USA 2002, 99:526I-5266.

17. Wilson RC, Wei J, Cheng KC, Mercado AB, New MI: Rapid deoxyribonucleic acid analysis by allele-specific polymerase chain reaction for detection of mutations in the steroid $2 \mathrm{I}$-hydroxylase gene. J Clin Endocrinol Metab 1995, 80: 1635-1640.

18. Keen-Kim D, Redman JB, Alanes RU, Eachus MM, Wilson RC, New MI, Nakamoto JM, Fenwick RG: Validation and clinical application of a locus-specific polymerase chain reaction- and minisequencing-based assay for congenital adrenal hyperplasia (2I-hydroxylase deficiency). J Mol Diagn 2005, 7:236-246.

19. Baumgartner-Parzer SM, Nowotny P, Heinze G, Wäldhausl W, Vierhapper $\mathrm{H}$ : Carrier frequency of congenital adrenal hyperplasia ( 21 -hydroxylase deficiency) in a middle European population. J Clin Endocrinol Metab 2005, 90:775-778.

20. The MHC Haplotype Project [http://www.sanger.ac.uk/HGP/ Chr6/MHC/index.shtml]

21. Stewart CA, Horton R, Allcock RJ, Ashurst JL, Atrazhev AM, Coggil P, Dunham I, Forbes S, Halls K, Howson JM, Humphray SJ, Hunt S, Mungall AJ, Osoegawa K, Palmer S, Roberts AN, Rogers ], Sims S, Wang Y, Wilming LG, Elliott JF, de Jong PJ, Sawcer S, Todd JA, Trowsdale J, Beck S: Complete MHC haplotype sequencing for common disease gene mapping. Genome Res 2004, 1 4: I 176-I I87.

22. Smith WP, Vu Q, Li SS, Hansen JA, Zhao LP, Geraghty DE: Toward understanding MHC disease associations: partial resequencing of 46 distinct HLA haplotypes. Genomics 2006, 87:56 I-7I.

23. White PC, Speiser PW: Congenital adrenal hyperplasia due to 2 I-hydroxylase deficiency. Endocr Rev 21:245-291.

24. Curin JM, Terzic J, Petkovic ZB, Zekan L, Terzic IM, Susnjara IM Lower cortisol and higher ACTH levels in individuals with autism. J Autism Dev Disord 2003, 33:443-448.

25. Tordjman S, Ferrari P, Sulmont V, Duyme M, Roubertoux P: Androgenic activity in autism. Am J Psychiatry 1997, 154:1626-1627.

26. Knickmeyer R, Baron-Cohen S, Fane BA, Wheelwright S, Mathews GA, Conway GS, Brook CG, Hines M: Androgens and autistic traits: A study of individuals with congenital adrenal hyperplasia. Horm Behav 2006, 50: |48-I53.

27. Knickmeyer R, Baron-Cohen S, Raggatt P, Taylor K: Foetal testosterone, social relationships, and restricted interests in children. J Child Psychol Psychiatry 2005, 46: I98-2I0.

28. Araújo RS, Mendonca BB, Barbosa AS, Lin CJ, Marcondes JA, Billerbeck AE, Bachega TA: Microconversion between CYP2IA2 and CYP2 IAIP promoter regions causes the nonclassical form of 21-hydroxylase deficiency. J Clin Endocrinol Metab 2007, 92:4028-4034. 


\section{Pre-publication history}

The pre-publication history for this paper can be accessed here:

http://www.biomedcentral.com/1471-2350/9/1/prepub

Publish with Bio Med Central and every scientist can read your work free of charge

"BioMed Central will be the most significant development for disseminating the results of biomedical research in our lifetime. " Sir Paul Nurse, Cancer Research UK

Your research papers will be:

- available free of charge to the entire biomedical community

- peer reviewed and published immediately upon acceptance

- cited in PubMed and archived on PubMed Central

- yours - you keep the copyright 